\title{
Identification of life habits factors as risk for gastritis and colitis occurrence in a mestizo population of Chabeklumil, Chiapas, México
}

\author{
Diana Cecilia Tapia-Pancardo ${ }^{{ }^{*}}$, Ramiro Jesús-Sandoval ${ }^{2}$, Myrna Miriam Valera-Mota $^{3}$, \\ José Luis Cadena-Anguiano ${ }^{4}$, Miguel Murguía-Romero ${ }^{1}$, Rafael Villalobos-Molina ${ }^{1}$ \\ ${ }^{1}$ División de Investigación y Posgrado, FES Iztacala, Universidad Nacional Autónoma de México, Tlalnepantla, México \\ ${ }^{2}$ Carrera de Médico Cirujano, FES Iztacala, Universidad Nacional Autónoma de México, Tlalnepantla, México \\ ${ }^{3}$ Carrera de Optometría, FES Iztacala, Universidad Nacional Autónoma de México, Tlalnepantla, México \\ ${ }^{4}$ Carrera de Cirujano Dentista, FES Iztacala, Universidad Nacional Autónoma de México, Tlalnepantla, México \\ Email: *dianacecitapia@hotmail.com
}

Received 15 November 2011; revised 30 January 2012; accepted 15 February 2012

\begin{abstract}
Aim: Gastric diseases are a recent trend in morbidity in México. We aimed to identify most frequent life habits factors as risk for gastritis and colitis occurrence, in a Mexican mestizo population in Chabeklumil, Chiapas. Population: This study was observational, descriptive, transversal and prospective; 346 questionnaires were applied to individuals of both genders from 11 years of age, with low income and socio-economic status, after they signed the informed consent. An individual file was created by the nurses in Chabeklumil. The predominant gender in the population was female $(56.1 \%)$, with a distribution of 166 among adulthood (19 - 59 years of age); among males (43.9\%), 133 included adults. Results: We identified the following environmental risk factors to develop gastritis and colitis: long periods of daily fasting $>$ consumption of irritant food and drink > stress, in females; in contrast, males reported alcohol and tobacco consumption $>$ irritant food and drink $>$ long periods of daily fasting $>$ stress. We found statistical differences $(P<0.05)$ in risk factors between females and males, in drugs and alcohol consumption, fasting, and stress, but not in consumption of irritant foods, nor in colitis and gastritis prevalence. Conclusions: Females are most affected by life habits risk factors for gastritis/colitis, which occurs mainly due to lifestyle and "macho" culture, since women are precluded of a better living standard, they work hard in the field, and start early in the day without consuming a meal, which they eat late in the day once arriving home. People in Chabeklumil eat/drink a lot of irritant food like hot pepper and coffee, which
\end{abstract}

${ }^{*}$ Corresponding author. damage the gastrointestinal system leading to gastritis and colitis. Furthermore, men started to consume drugs at early ages, a condition also involved in developing gastritis.

Keywords: Gastritis; Colitis; Life Habits Risk Factors; Poverty; Mexican Mestizo Population

\section{INTRODUCTION}

In México lifestyle, culture and economic resources of its inhabitants have modified morbidity trends in the last decade; such that gastritis became the fourth new disease in the population, and is growing since consumption of irritant food and drinks is raising [1]. Then, chronic gastritis has been associated with peptic ulcer and in advanced stages with the development of gastric adenocarcinoma [2].

On the other hand, severe forms of gastric disease have been associated to Helicobacter pylori infection, and it is known that in developing countries prevalence of the bacterium is $80 \%-90 \%$ among middle-aged adults, while it is $20 \%-50 \%$ in developed countries [3-6]. Therefore, H. pylori infection is a necessary but not a sufficient cause for those pathologies. In support of this contention there is a recent report where patients with $H$. pylori infection showed no significant difference from bacterium-free patients [7]. Furthermore, recent data suggest that $H$. pylori presence in the gastrointestinal tract might be a normal colonization of the bacterium in the gastric microbiome, rather than an infection per se [8]. So, it is important to study other factors that might be involved in gastritis and colitis occurrence $[3,9,10]$.

In that regard, Mexican territory is formed by 31 States and 1 Federal District, and among them many 
rural communities of extreme poverty do exist. Chiapas State accounts for many counties ("Municipios") in extreme poverty conditions; one of these communities is Chabeklumil, located in "Municipio" Sitalá showing a population of 10,246 [1].

Chabeklumil is an agricultural community where coffee and hot peppers are the main crops, which are involved in their daily consumption by the population [11]. Moreover, people work for long periods of time during each day exposed to sunshine, they are subjected to fasting for many hours and eat late once arriving home, mainly irritant foods; in addition, they lack basic services like electricity, tap water and sewage [11]. All together, these conditions seem to favor gastritis and colitis occurrence $[12,13]$. Therefore we aimed to identify which are those factors that, according to gender, age, and lifestyle favor gastritis and/or colitis occurrence in the inhabitants of Chabeklumil, Sitalá, Chiapas.

\section{METHOD}

\subsection{Design}

The study was observational, descriptive, transversal and prospective.

\subsection{Sample Selection}

The participants were field workers with low income and socio-economic status. A file was created for each individual by the nurses in Chabeklumil, a community located in the south of México. Participants (346) of both genders, from 11 years of age completed the questionnaire. The questionnaire included variables such as fasting period, irritant food and drink consumption, stress, alcohol consumption, smoking habits, demographic information and socio-economic aspects. Subjects also had to reside within $40 \mathrm{~km}$ of Chabeklumil and have an identifiable address. In addition, we gave them information for prevention and treatment of their illnesses.

\subsection{Data Collection}

All the data were collected by experienced nurses at the public plaza in Chabeklumil town. The participants received verbal and written information about the purpose of the study, its procedure, and the nature of their voluntary participation. Written consent/finger printing was obtained from all the participants in this study. Once the participants agreed, they were asked to fill out a questionnaire on their socio-demographic information and health behavior. All the assessments were completed in $1 \mathrm{~h}$.

\subsection{Ethical Approval}

The Ministry of Social Development (SEDESOL, Méxi- co), and Facultad de Estudios Superiores Iztacala (U.N. A.M.) Ethical Committees found the study protocol's formal approval unnecessary, and it is part of a Program for High Poverty Community Assistance (Estrategia 100 $\times 100$ ). In addition, we gave them information for prevention and treatment of their illnesses.

\subsection{Analysis}

A descriptive analysis was carried out in order to analyze the distribution of the variables. To establish statistical significance of life habits risk factors among males and females a Z-test for proportions was applied, with a critical value of $5 \%$.

\section{RESULTS}

\subsection{Socio-Demographic Data}

The predominant gender in the working population of Chabeklumil was female $(56.1 \%, 194$ women), most of them were adult (48\% women, 19 - 59 years of age, Table 1); whereas males accounted for 152 (43.9\% men), most in the adulthood ( $38 \%$ men, Table 1).

\subsection{Gastritis and/or Colitis and Risk Factors Prevalence}

The female inhabitants of Chabeklumil exposed to risk factors that filled up the questionnaire for gastric illnesses were 194, from them 58 showed initial symptoms of gastritis and/or colitis, such as: discomfort in the epigastric area, abdominal pain, diarrhea, colics. The observed frequency for gastritis was: 50 adults, 6 adolescents, and 2 elderly (Table 2). In contrast, 136 women showed typical signs and symptoms for gastritis/colitis, i.e., dyspepsia, feeling of fullness or burning in the epigastric area, constant abdominal pain, and the observed frequency was: 68 showed gastritis, 44 colitis, and 24 both illnesses (Table 2).

Regarding male population, 152 of them filled the questionnaire and 60 males showed initial symptoms of the diseases, where 52 were adult, 6 adolescents and 2 elderly (Table 2); while 92 men showed clear signs and

Table 1. Socio-Demographic data of inhabitants of Chabeklumil, Sitalá, Chiapas (346 clinical files, 2007), grouped by age ranges: Adolescents (11 - 18 years old), Adults (19 - 59 years old), Elderly ( $>60$ years old).

\begin{tabular}{ccccc}
\hline & Females & Males & \multicolumn{2}{c}{ Total } \\
\hline Adolescents & 20 & 18 & 38 & $11.0 \%$ \\
Adults & 166 & 130 & 296 & $85.5 \%$ \\
Elderly & 8 & 4 & 12 & $3.5 \%$ \\
Total & $\mathbf{1 9 4}$ & $\mathbf{1 5 2}$ & $\mathbf{3 4 6}$ & $\mathbf{1 0 0 . 0 \%}$ \\
\hline
\end{tabular}


Table 2. Population of Chabeklumil, Sitalá, Chiapas showing clear symptoms for gastritis and/or colitis (G-C), and population without G-C by main risk factor.

\begin{tabular}{|c|c|c|c|c|c|c|}
\hline & \multicolumn{2}{|c|}{ Female } & \multicolumn{2}{|c|}{ Male } & \multicolumn{2}{|c|}{ Total } \\
\hline \multicolumn{7}{|c|}{ Populations showing clear symptoms for gastritis and/or colitis } \\
\hline Gastritis & 68 & $50.0 \%$ & 55 & $59.8 \%$ & 123 & $53.9 \%$ \\
\hline Colitis & 44 & $32.4 \%$ & 28 & $30.4 \%$ & 72 & $31.6 \%$ \\
\hline Gastritis + Colitis & 24 & $17.6 \%$ & 9 & $9.8 \%$ & 33 & $14.5 \%$ \\
\hline Total & 136 & $100.0 \%$ & 92 & $100.0 \%$ & 228 & $100.0 \%$ \\
\hline \multicolumn{7}{|c|}{ Main risk factor of population without initial symptoms for gastritis and/or colitis } \\
\hline Drugs consumption $^{*}$ & 0 & $0.0 \%$ & 29 & $48.3 \%$ & 29 & $24.6 \%$ \\
\hline Irritant foods & 21 & $36.2 \%$ & 24 & $40.0 \%$ & 45 & $38.1 \%$ \\
\hline Fasting ${ }^{*}$ & 22 & $37.9 \%$ & 5 & $8.3 \%$ & 27 & $22.9 \%$ \\
\hline Stress $^{*}$ & 15 & $25.9 \%$ & 2 & $3.3 \%$ & 17 & $14.4 \%$ \\
\hline Total & 58 & $100.0 \%$ & 60 & $100.0 \%$ & 118 & $100.0 \%$ \\
\hline Total population studied & 194 & & 152 & & 346 & \\
\hline
\end{tabular}

${ }^{*} \mathrm{P}<0.05$ for proportions between females and males.

symptoms of gastritis and/or colitis: we found that 55 men showed gastritis, while 28 had colitis, and 9 bear gastritis and colitis (Table 2). No significant differences were found in colitis and gastritis prevalence between females and males.

When females were questioned about life habits risk factors that could cause them gastritis/colitis, the answers were: irritant food and drink consumption $>$ long fasting periods $>$ stress (Table 2). Regarding males, the answers were: alcohol and tobacco consumption $>$ irritant food and drink consumption $>$ long fasting periods $>$ stress (Table 2).

When females were compared with males, significant differences $(\mathrm{P}<0.05)$ were found in risk factors such as drugs and alcohol consumption (women did not report consumption), fasting (females $>$ males), and stress (females $>$ males); no difference was obtained in consumption of irritant foods and beverages.

\section{METHODOLOGICAL CONSIDERATIONS}

It is important to mention that health professionals should be more involved in providing education to indigenous and poorer communities, with the goal to diminish disease risk factors favoring a better life quality.

\section{DISCUSSION}

Gastric diseases have been on the raise around the world, and their etiology is mainly associated to $H$. pylori infection $[2,3,8,13]$. However, even though half of the human population seems to carry the bacterium its incidence varies, from $20 \%-50 \%$ in industrialized nations to $80 \%$ $90 \%$ in developing countries $[5,6,12]$, which means that gastric diseases do occur by $H$. pylori infection and/or other causes [7,9]. Moreover, there is controversy among the putative infection pathways for the bacterium to colonize the human stomach, since no clear evidence exists from oral-oral, fecal-oral or food-borne transmission $[3,13,14]$.

In contrast, lifestyle factors such as income, education, diet, drugs consumption, and control over life are associated with health self-evaluation and chronic diseases [10, 14-18]. In this regard, Chiapas population is about $4,293,459$, where $52 \%$ of them inhabit rural zones. It is worth to mention that 12 out of 62 indigenous ethnic groups in México are located in Chiapas, with about 1 million persons. These data show a panorama where extreme poverty conditions do exist in Chabeklumil, which involve analphabetism, low income wages, lack of water pipelines, lack of sewage, disperse health centers located far away from small towns, hard work in the field in order to earn some money, long fasting periods, long time sunshine exposure, and "macho" culture where alcohol and tobacco consumption are very frequent, and which preclude women to acquire a better living standard. In addition, a recent study in young Mexicans (17 - 24 years old) showed that Chiapas is one of México States with the lowest prevalence of metabolic syndrome and obesity, nutrition-associated conditions that could be related to poverty in this State [19].

All together, H. pylori infection which putatively is 
involved in $80 \%-90 \%$ of gastric diseases in poor people $[4,10,20]$, along with the living conditions that Chabeklumil inhabitants face routinely, might explain why the majority of the interviewed population have shown the signs and symptoms for gastritis and/or colitis; while others are already with initial symptoms of the diseases. In support of this contention, it has been shown that 1 week administration of a combination of omeprazole, amoxicillin, and clarithromycin eradicated H. pylori in higher than $70 \%$ of persons at risk for gastric illness, which means that both pharmacological treatment against the bacteria, and better living standard will improve population's health regarding gastric diseases.

In our study females are most affected by risk factors for gastritis/colitis, which occur mainly due to lifestyle and "macho" culture, since them face a poor living standard, they work hard in the field, and start early in the day without consuming a meal, which they eat late in the day once arriving home. People in Chabeklumil eat/drink a lot of irritant food like hot pepper and coffee, which damage the gastrointestinal system leading to gastritis and colitis. Furthermore, men started to consume drugs at early ages, a condition also involved in developing gastritis.

\section{CONCLUSION}

Females are most affected by risk factors for gastritis/ colitis, which occur mainly due to lifestyle and "macho" culture. Women are precluded of a better living standard, since they work hard in the field, start early in the day without consuming a meal, and they eat/drink late a lot of irritant food like hot pepper and coffee. Furthermore, men started to consume drugs at early ages, a condition also involved in developing gastritis.

\section{ACKNOWLEDGEMENTS}

Authors wish to thank SEDESOL and authors (DCT-P, RV-M) for partial funding.

\section{REFERENCES}

[1] INEGI (2007) Counting of Population and Housing (in Spanish).

http://www.inegi.gob.mx/inegi/default.aspx?s=est\&c=10 $\underline{215}$

[2] Redéen, S., Petersson, F., Kechagias, S., Márdh, E. and Borch, K. (2010) Natural history of chronic gastritis in a population-based cohort. Scandiavian Journal of Gastroenterology, 45, 540-549. doi:10.3109/00365521003624151

[3] Van Duynhoven, Y.T. and De Jonge, R. (2001) Transmission of Helicobacter pylori: A role for food? Bulletin of the World Health Organization, 79, 455-460.
[4] Frenck, R. W. Jr. and Clemens, J. (2003) Helicobacter in the developing world. Microbes Infection, 5, 705-713. doi:0.1016/S1286-4579(03)00112-6

[5] Herrera-Goepfert, R., Yamamoto-Furusho, J.K., OnateOcana, L.F., Camorlinga-Ponce, M., Munoz, L., RuizMorales, J.A., Vargas-Alarcon, G. and Granados, J. (2006) Role of the HLA-DQ locus in the development of chronic gastritis and gastric carcinoma in Mexican patients. World Journal of Gastroenterology, 12, 7762-7767.

[6] Romo-Gonzalez, C., Salama, N.R., Burgeño-Ferreira, J., Ponce-Castañeda, V., Lazcano-Ponce, E., CamorlingaPonce, M. and Torres J. (2009) Differences in genome content among Helicobacter pylori isolates from patients with gastritis, duodenal ulcer, or gastric cancer reveal novel disease-associated genes. Infection and Immunology, 77, 2201-2211. doi:10.1128/IAI.01284-08

[7] Qiu, H.-B., Zhang, L.-Y., Keshari, R.-P., Wang, G.-Q., Zhou, Z.-W., Xu, D.-Z., Wang, W., Zhan, Y.-Q. and Li, W. (2010) Relationship between $H$. pylori infection and clinicopathological features and prognosis of gastric cancer. BMC Cancer, 10, 374-382. doi:10.1186/1471-2407-10-374

[8] Dorer, M.S., Talarico, S. and Salama, N.R. (2009) Helicobacter pylori's unconventional role in health and disease. PLoS Pathogens, 5, e1000544. doi:10.1371/journal.ppat.1000544

[9] Salih, B.A., Abasiyanik, M.F., Bayyurt, N. and Sander, E. (2007) H. pylori infection and other risk factors associated with peptic ulcers in Turkish patients: A retrospective study. World Journal of Gastroenterology, 13, 3245 3248 .

[10] Zhang, L., Eslick, G.D., Xia, H.-X., Wu, C., Phung, N. and Talley, N.J. (2010) Relationship between alcohol consumption and active Helicobacter pylori infection. Alcohol Alcoholism, 45, 89-94. doi:10.1093/alcalc/agp068

[11] Anonym (2007) Agriculture, coffee and chile pepper in Chiapas (in Spanish). http://www.sagarpa.gob.mx

[12] Moraes, M.M.C. and Da Silva, G.A.P. (2003) Risk factors for Helicobacter pylori infection in children. Journal of Pediatry, 79, 21-28. doi:10.2223/JPED.933

[13] Vale, F.F. and Vítor, J.M.B. (2010) Transmission pathway of Helicobacter pylori: Does food play a role in rural and urban areas? International Journal of Food Microbiology, 138, 1-12. doi:10.1016/j.ijfoodmicro.2010.01.016

[14] Nneli, R.O., Nwafia, W.C. and Orji, J.O. (2007) Diets/dietary habits and certain gastrointestinal disorders in the tropics: A review. Nigerian Journal of Physiological Sciences, 22, 1-13.

[15] Brenner, H., Rothenbacher, D., Bode, G. and Adler, G. (1999) Inverse graded relation between alcohol consumption and active infection with Helicobacter pylori. American Journal of Epidemiology, 149, 571-576.

[16] Ito, L.S., Oba-Shinjo, S.M., Marie, S.K., Uno, M., Shinjo, S.K., Hamajima, N., Tajima, K. and Tominaga, S. (2003) Lifestyle factors associated with atrophic gastritis among Helicobacter pylori seropositive Japanese-Brazilians in São Paulo. International Journal of Clinical Oncology, 8, 
362-368. doi:10.1007/s10147-003-0355-3

[17] Stelmach, W., Kaczmarczyk-Chałas, K., Bielecki, W. and Drygas, W. (2004) The association between income, education, control over life and health in a large urban population of Poland. International Journal of Occupational Medicine and Environmental Health, 17, 299-310.

[18] Izzotti, A., Durando, P., Ansaldi, F., Gianiorio, F. and Pulliero, A.I. (2009) Interaction between Helicobacter pylori, diet, and genetic polymorphisms as related to noncancer diseases. Mutation Research, 667, 142-157. doi:10.1016/j.mrfmmm.2009.02.002
[19] Murguía-Romero, M., Jiménez-Flores, R., VillalobosMolina, R. and Méndez-Cruz, R. (2012) Estimating the geographic distribution of the prevalence of the metabolic syndrome in young Mexicans. Geospatial Health, in press.

[20] Mohar, A., Ley, C., Guarner, J., Herrera-Goepfert, R., Figueroa, L.S., Halperin, D. and Parsonnet, J. (2002) Eradication rate of Helicobacter pylori in a Mexican population at high risk for gastric cancer and use of serology to assess cure. American Journal of Gastroenterology, 97, 2530-2535. doi:10.1111/j.1572-0241.2002.06035.x 